\title{
Accessibility patterns: Baltic States Case Study ${ }^{1}$
}

\author{
Carsten Schürmann \\ RRG Spatial Planning and Geoinformation \\ Eichenweg 16, D-23758 Oldenburg i.H., Deutschland, Germany \\ cs@brrg.de
}

\begin{abstract}
The Baltic States' accessibility analysis managed to depict the various accessibility patterns in these areas successfully. The results illustrate different accessibility levels for different indicators, for different modes, for different types of regions, for different spatial levels, as well as for different years. Generally, accessibility levels by car are much higher opposed to those by public transport due to rather low service quality of railway and bus systems in many parts of the Baltic States. While for some indicators (e.g. access to health care facilities, travel time to the nearest regional centre) there is good and almost equal accessibility throughout the case study area, there are remarkable disparities for other indicators (daily accessibility of jobs, potential accessibility to the population) within the Baltic States as a whole, but also within individual countries, so as between modes. These findings emphasise that one indicator alone cannot capture the full picture of accessibility patterns in a region.
\end{abstract}

Keywords: accessibility, transport infrastructure, accessibility pattern, TEN-T, GIS, raster approach, Baltic States.

\section{Case study introduction}

One of the seven case studies of the TRACC project is the Baltic States case study region. This case study region was selected as it represents peripheral, sparsely populated regions in the new EU Member States, with rigorous climates, which underwent transition from republics of the Former Soviet Union to independent countries. In order to be of comparable size with the other six case studies in terms of the area and population coverage, all three Baltic States were merged under one case study.

1 This paper has been developed under the applied research project TRansport ACCessibility at regional/local scale and patterns in Europe led by Spiekermann \& Wegener Urban and Regional Research (S\&W) Germany. It has been financed by the ESPON 2013 Programme and its financial support is gratefully acknowledged. Texts, maps and conclusions stemming from research projects under the ESPON programme presented in this paper do not necessarily reflect the opinions of the ESPON Monitoring Committee. C ESPON, 2013. 


\section{Spatial structure}

All the three Baltic States are primarily rural countries with generally low population densities, lacking a system of cities and agglomerations. Only the capital city regions and, to some extent, the seaports are agglomerated areas, concentrating most of the private and public services and capital. The other parts of the countries are rural areas, with small and medium-sized towns with population of less than 25,000, often less than 5,000, resulting in extremely poor population densities of less than 50 people per $\mathrm{km}^{2}$ (Estonia: 30 people $/ \mathrm{km}^{2}$, Lithuania: 52 people $/ \mathrm{km}^{2}$; Latvia: 35 people $/ \mathrm{km}^{2}$ ) (Wikipedia, 2012a; 2012b; 2012c).

Altogether, nowadays some 6.7 million people live in the three Baltic States, with 3.2 million people in Lithuania, 2.2 million people in Latvia and 1.3 million people in Estonia. In all three countries, the population is clearly concentrated in the capital regions; only few other cities are of substantial size, which are the Baltic Sea ports, and some regional hinterland cities.

Most of the cities and towns in the Baltic States experienced a population decline in the last decade (Schmitt et al., 2008, 19), only the capital cities remained stable in terms of the population in this period. In the case of Klaipeda and Riga city regions, some suburbanisation processes have been observed since 2000, while the surrounding smaller towns increased population over-proportionally compared to the core city.

\section{Socio-economic situation}

Despite its annual economic growth rate of 5-6\% since 2000 (from very low levels, though), the economic performance of the overall macro region is still poor, with employment rates and GDP per capita of only $25-50 \%$ of the EU-27 average. Only the three capital city regions reach the European average.

GDP per capita is the highest in Estonia (USD 15,850) followed by Lithuania (USD 14,273) and Latvia (USD 11,985) (Wikipedia, 2012a; 2012b; 2012c). The dominance in the primary sector, in particular in Latvia and Lithuania, underlines the predominantly rural character of the macro region. The human development index (HDI) is quite high for all the three countries, ranging from 0.769 for Latvia to 0.812 for Estonia, compared to other continents, but at the lower end of the spectrum compared to the European Union average, where most countries display HDI numbers above 0.85 (UNDP, 2012).

In Estonia, about $60 \%$ of national GDP is generated in the greater Tallinn area (Harjumaa), for trade and services alone the share is even $70 \%$. The primary sector is concentrated in central and southern Estonia, while the energy sector is concentrated in the north-east, close to the Russian border.

In all the three countries there is a high concentration of employment in the capital city regions, as well as in the ports (Pärnu, Ventspils, Liepaya, Klaipeda). There are only a few landlocked cities such as Tartu (Estonia), Daugavpils, Rezekne and Valmiere (Latvia), and Siauliai, Panevezyz and Kaunas (Lithuania) acting as regional economic and employment centres for their rural hinterland.

Previous accessibility studies revealed that only the capitals gained accessibility levels above the EU-27 average, while all other parts of the countries lagged significantly behind in terms of the population potential, accessibility to the population and also accessibility to GDP, with accessibility levels in the European context similar to those of peripheral territories in northern Scandinavia, not only due to the extremely low population densities, but also due to absence of high-quality transport infrastructure. 


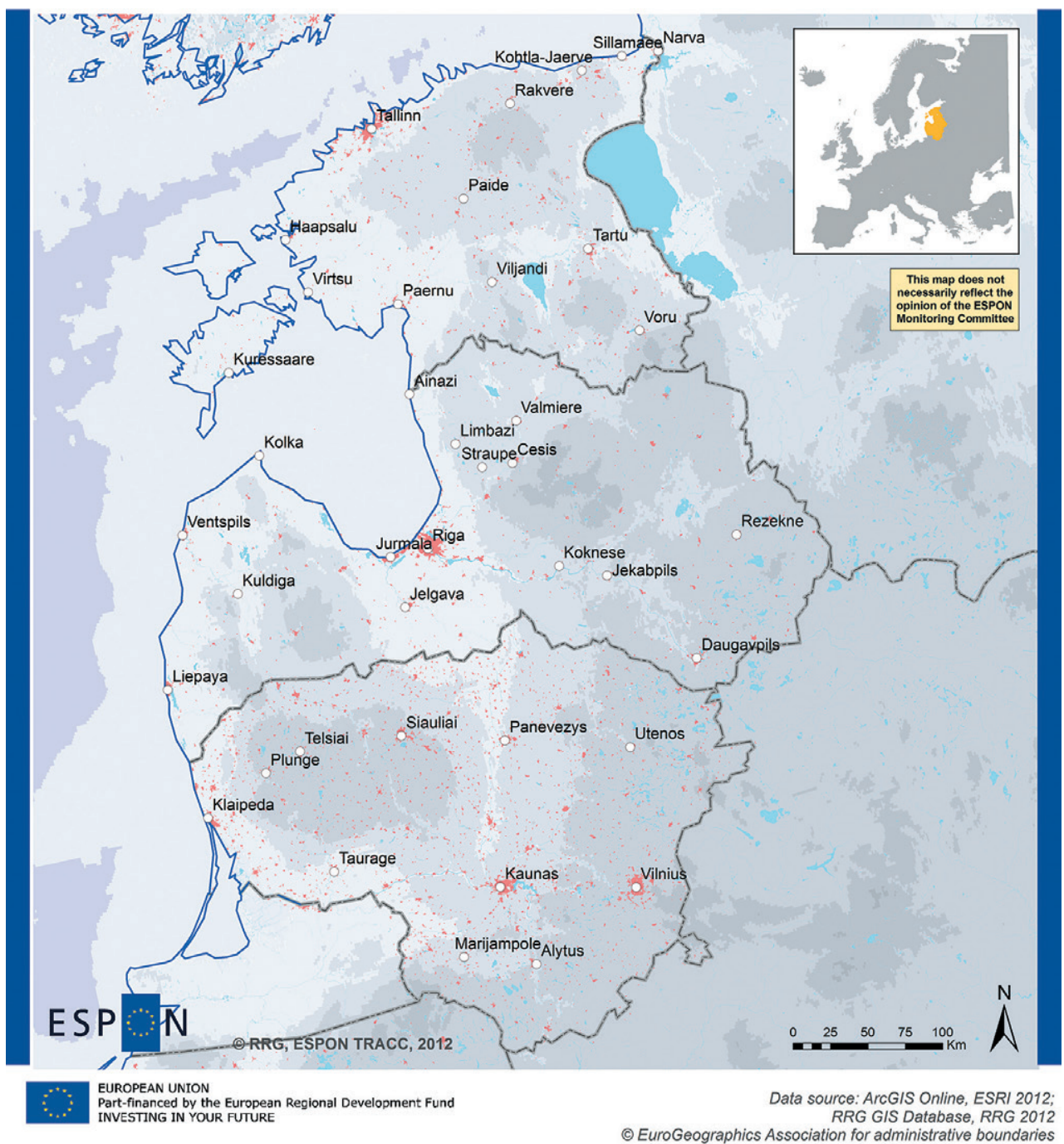

\title{
Baltic States Case Study Physical map
}

\author{
○. Main city \\ Settlement area
}

Figure 1. Baltis States case study region.

\section{Transport aspects}

Generally, the transport systems in the Baltic States still reflect the infrastructures of the past to a large degree, when the three countries were part of the Soviet Union. Density, quality and orientation of the main transport arteries to date still represent former traffic and goods flows. After the 
transition from the Soviet Union to independent states, the transport systems reveal some severe immanent problems:

- A major obstacle to transport is the general layout of the main transport infrastructure: for historical reasons all main road and rail infrastructures are west-east oriented, connecting central parts of Russia with Baltic Sea seaports. Until today, this remains the main trade flow direction in this area (see Böhme et al., 1998). In contrast, north-south oriented transport arteries are very scarce and, if they exist, are often of poor quality. For instance, to date there is no direct north-south train connection from Poland to Tallinn (Dubois and Schürmann, 2009, 549). This is a major obstacle for the three capital city regions of Vilnius, Riga and Tallinn to move closer together.

- All three countries are lacking high-level transport systems, such as motorways or high-speed train sections. There are only few motorway and dual-carriageway sections, opened to traffic only recently, and almost no high-quality railway lines. The remaining road networks are preliminary designed to meet regional transport demand rather than long-distance inter-city traffic.

- A recent UN ECE survey revealed that the secondary road networks developed differently in the three countries: while for Lithuania (140\%) and Estonia (125\%) these networks increased significantly since the beginning of the 1990s, the lengths of these networks in Latvia declined to $92 \%$ in the same period (UNECE, 2008).

- While the general density of the road networks is quite good, the density of the rail networks is rather low in the Baltic States. Apart from the main railway lines connecting the capital cities with the main ports and with Russia, almost no substantial rail links are available (RRG, 2012). In addition, many of the existing lines suffer from poor conditions due to lack of maintenance, recently resulting in ceased passenger traffic.

- All three countries have at least one major ferry seaport which is tightly embedded into Baltic Sea shipping networks, but none of the countries has any inland waterway network that would allow feeder-shipping services from/to the main ferry hubs. Therefore, all incoming goods must be transhipped in the ferry seaports to road and railway services. Unfortunately, the hinterland connections of these ports are of low quality as well. Some of the ferry services connecting Baltic seaports belong to the top 25 connections in terms of the number of weekly ferry services (for instance, the Helsinki-Tallinn ferry ranked 3rd with 392 weekly ferry services in 2007) (Schmitt et al., 2008, 83).

- Each of the three countries has one international airport in the capital city region. Even though the airports provide quite a number of services to various countries, the number of direct destinations served is rather low compared to major airports in Central Europe (OAG, 2012). Since there are no other commercial airports in these countries except the three main ones, all commercial air services have to go through these three, which requires good accessibility of these airports in the regional context. Unfortunately, this is the case only to some degree.

Altogether, there is no high-quality transport infrastructure interconnecting the three Baltic States. The present TEN-T outline plans attempt to overcome this handicap by implementing new prioritised road and rail axes in the north-south direction, connecting Tallinn in the north with Poland in the south (European Commission, 2011). 


\section{Accessibility patterns}

In order to analyse the accessibility patterns on a regional and local scale for the Baltic States, four accessibility indicators: daily accessibility of jobs by car, regional accessibility potential by car, access to regional centre by public transport, and access to health care facilities by car have been calculated at the raster level with a resolution of $2.5 \times 2.5 \mathrm{~km}$ for all the three countries. The analyses follow the common methodology described by Biosca et al. (2013).

\section{Daily accessibility of jobs by car}

This indicator approaches the opportunities of the regional labour market from the point of view of the population. For each raster cell, the number of jobs reachable within a maximum commuting distance of 60 minutes by car is estimated.

There are large differences in job accessibility (Figure 1). While from places along the borders people can only reach up to 5,000 jobs, contrary to the best accessible places where people can reach more than 750,000 jobs within 60 minutes' travel time by car. The latter areas are the greater Riga agglomeration, as well as the area between Kaunas and Vilnius in Lithuania. Estonia has two labour market centres, namely Tallinn and Tartu. However due to the generally lower population of Estonia these two areas do not yield as high accessibility values as the other two areas. While Riga dominates the accessibility surface for Latvia, the situation in Lithuania is more interesting since the centres of Klaipeda, Siauliai and Parnevezys form individual distinct labour markets where people can reach between 100,000 and 500,000 jobs. While accessibility ranges between the minimum and the maximum are the highest in Latvia, Lithuania on average shows the highest general accessibility level throughout the country. Apart from the two main labour market areas, job accessibility in Estonia is rather low with most places yielding rather small figures: between 10,000 and 100,000 jobs.

$50 \%$ of the population in the entire case study area can reach 280,000 jobs. In urban regions, some $5 \%$ of the most privileged population can reach up to 800,000 jobs, while in rural regions $90 \%$ of the population can reach 500,000 jobs at maximum, illustrating the great differences in accessibility surfaces between the two different types of regions. In brief, this accessibility indicator yields not only obvious differences and specific spatial patterns between the three Baltic States, but also between the two types of regions, with a strong concentration on the agglomerations.

\section{Regional accessibility potential by car}

What is the regional population potential of any point in space? In order to evaluate the different locations within a region from the viewpoint of economic actors, e.g. companies assessing the regional labour markets and locational advantages, or retail industries assessing the market area, the population potential is analysed, calculated as the sum of people in destination areas weighted by the travel times to reach them.

Regional potential accessibility to the population is much higher in Latvia and Lithuania compared to Estonia, due to the generally lower population densities in Estonia (Figure 2). The capital city regions clearly dominate the accessibility patterns in all the three countries. The accessibility surface around the major cities (Riga, Kaunas and Vilnius) forms plateaus of high accessibility, with stretches into the rural parts along the main transport axes.

Apart from the four leading agglomerations: Tallinn, Riga, Kaunas, and Vilnius, areas of average potential accessibility can be found around the regional cities of Klaipeda, Siauliai, Parnevezys, 
Daugavpils and Tartu. All other territories of the three Baltic States show accessibility levels far below the average, reaching only up to a quarter of the Baltic States' average.

In consequence, $50 \%$ of the population in rural regions gain index value of mere 45 , which means these regions are heavily underperforming compared to the overall average of the study area. In contrast, $50 \%$ of the population in urban regions observe accessibility index values of almost 170 , i.e. perform significantly above the average. The astonishing effect that intermediate regions belong to the best performers can be explained as intermediate regions between two major cities (like the area between Kaunas and Vilnius) benefit from short travel times to both cities, while either of the two cities itself has longer travel times to its counterpart.

\section{Access to regional centres by public transport}

This indicator analyses the travel time to the nearest regional centre, defined as a city with a population of more than 50,000 or a city being an important regional administrative centre.

Most areas in Lithuania and Latvia, and to a lesser degree but still a lot of areas in Estonia, yield travel times of more than 100 minutes to the nearest regional centre (Figure 3). Actually, many of these can be considered inaccessible by public transport since walking or cycling distance to the nearest bus stop or to the nearest railway station is beyond reasonable. To the contrary, there are small and distinct areas of high accessibility with travel times of less than 60 minutes, forming the main public transport axes (for instances, the axis from Tallinn via Paide to Tartu, the axis from Riga via Koknese and Jekabpils towards Rezekne, or another southbound axis from Klaipeda to Taurage, just to mention three). In the rural parts of the countries there are individual distinct 'spots' of high accessibility around the bus stops of cross-country busses or around railway stations, which are surrounded by areas of extremely low accessibility. Such spots are typically spatial patterns generated by public transport systems. Public transport does not span plateaus of high accessibility, but there are only individual service areas and axes. This means that if people can reach a regional centre at all within 60 or 30 minutes travel time, they can only reach one city.

An aggregated analysis by different types of urban and rural regional typologies once again revealed shorter travel times for urban regions and for intermediate regions close to a city, while travel times are significantly longer for intermediate remote and rural regions. For instance, for urban regions the 25 th percentile for public transport is about 40 minutes and the 75 th percentile is about 100 minutes, while for rural remote regions the 25 th percentile increased to 62 minutes and the 75 th percentile increased to 135 minutes.

The analysis of cumulative population distribution illustrates that only $70 \%$ of the overall population can reach a city by public transport in the same time span. For urban and intermediate regions $50 \%$ of the population can reach the nearest city in approx. 17 minutes, and $100 \%$ of the population within more than 150 minutes. In other words, there has been a significant drop in accessibility for the remaining predominantly rural population, who experience extremely poor service qualities in public transport.

\section{Access to health care facilities by car}

Hospitals clearly belong to major general services of public interest. This indicator measures the travel time necessary to reach the nearest hospital, where all hospitals offering general in-patient and surgical treatment are considered as destinations, while specialised clinics are not considered in this analysis. 


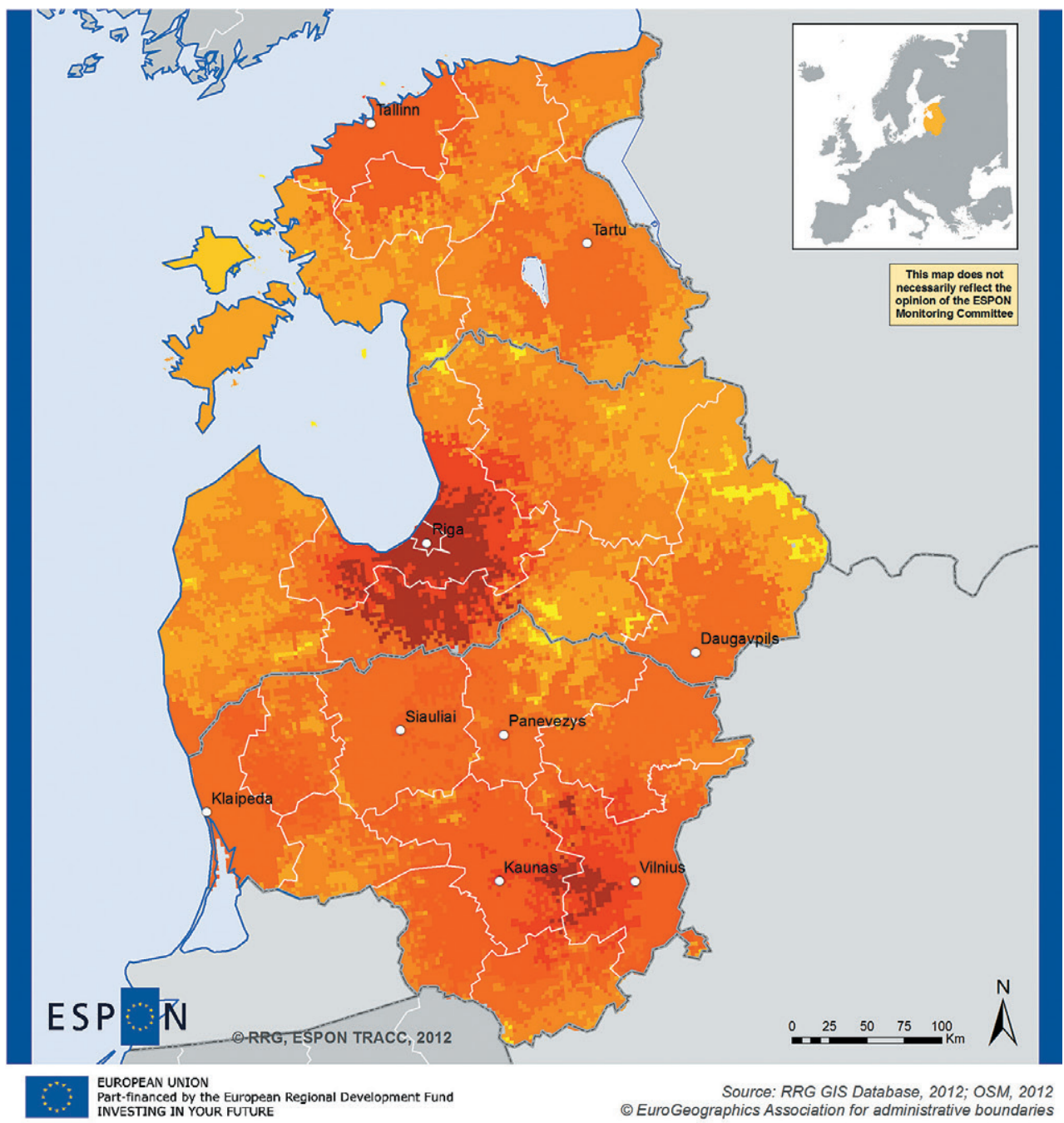

\section{Baltic States Case Study}

\section{Daily accessibility of jobs by road (2.5x2.5 km raster), 2012}

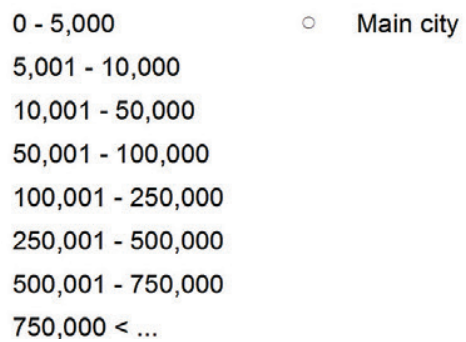

Figure 2. Jobs accessible within 60 minutes by car. 


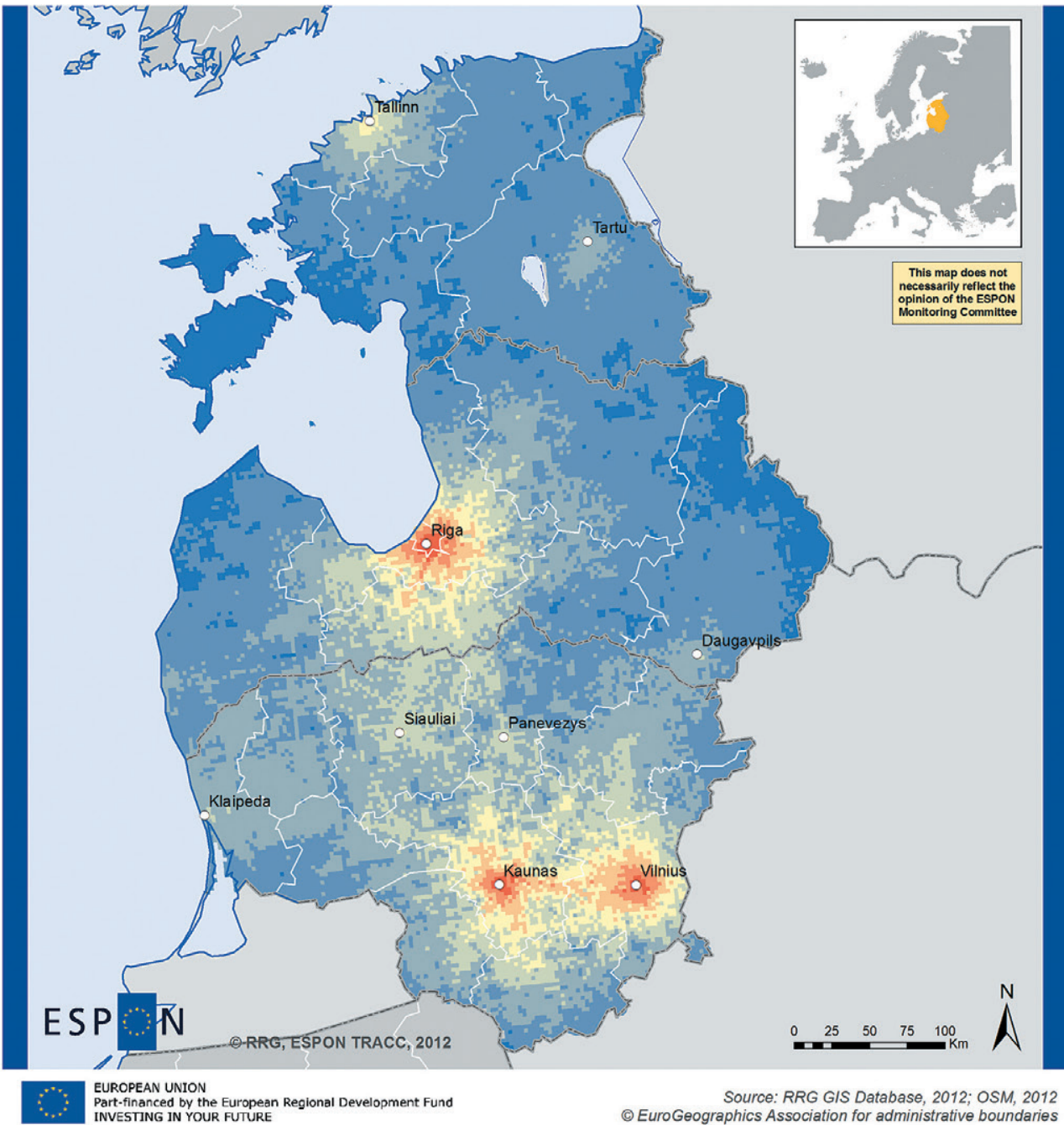

\section{Baltic States Case Study (2011) \\ Regional potential accessibility by road $(2.5 \times 2.5 \mathrm{~km}$ raster $)$}
$0-25$
$26-50$
$51-75$
$76-100$
$101-125$
$126-150$
$151-175$
$176-200$
$200<\ldots$

Notes:

Beta $=0.034657$

Minimum: 38,412

Average: 363,811

Maximum: 835,794

Figure 3. Potential accessibility to population by car. 


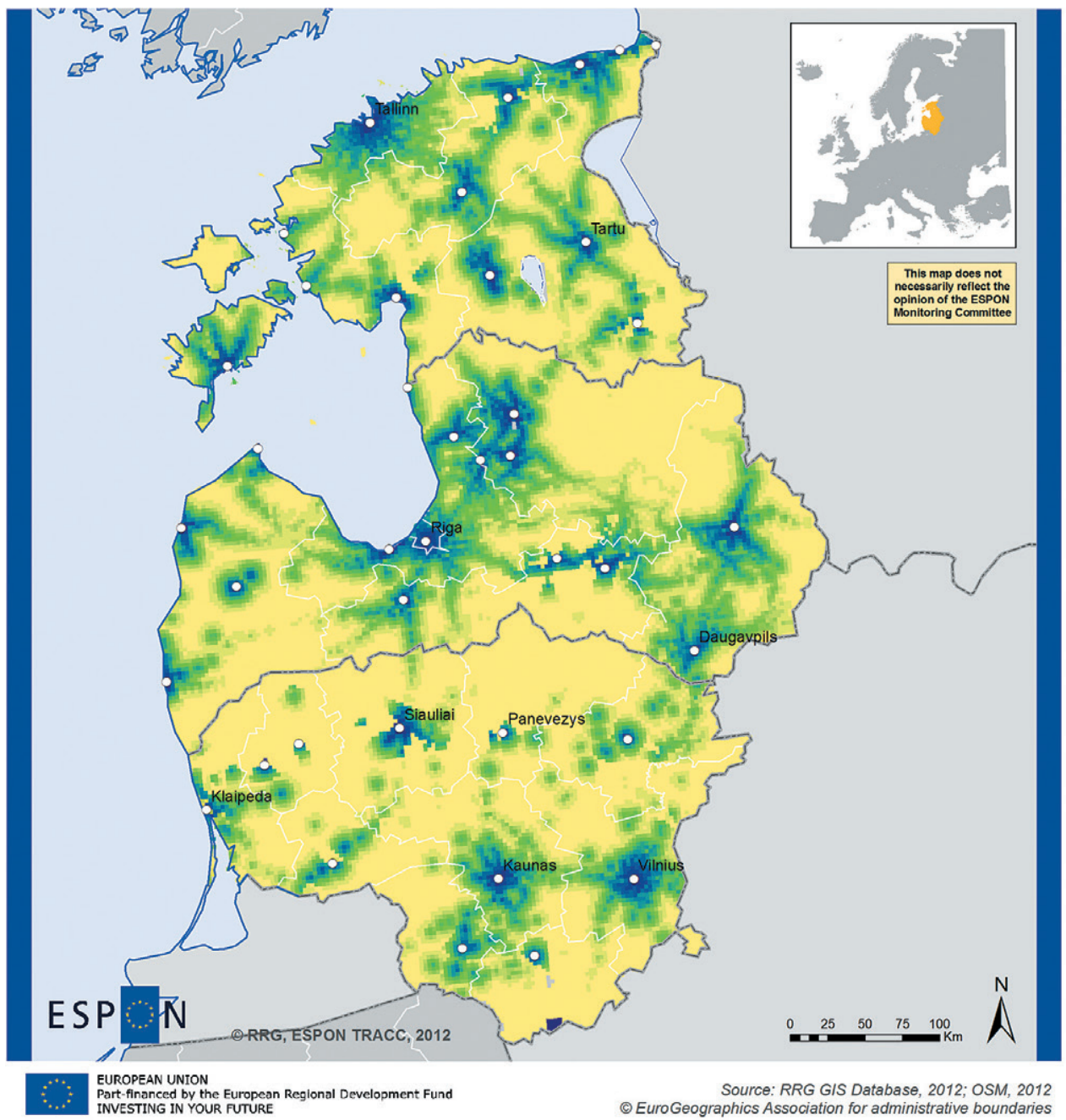

\section{Baltic States Case Study}

Travel time to nearest regional centre by public transport (min; $2.5 \times 2.5 \mathrm{~km}$ raster), 2012

\begin{tabular}{l|l|l}
$0-5$ & $31-35$ & $61-65$ \\
$6-10$ & $36-40$ & $66-70$ \\
$11-15$ & $41-45$ & $71-75$ \\
$16-20$ & $46-50$ & $76-80$ \\
$21-25$ & $51-55$ & $81-100$ \\
$26-30$ & $56-60$ & $101-400$
\end{tabular}

Figure 4. Travel time to nearest regional centre by public transport (raster level). 


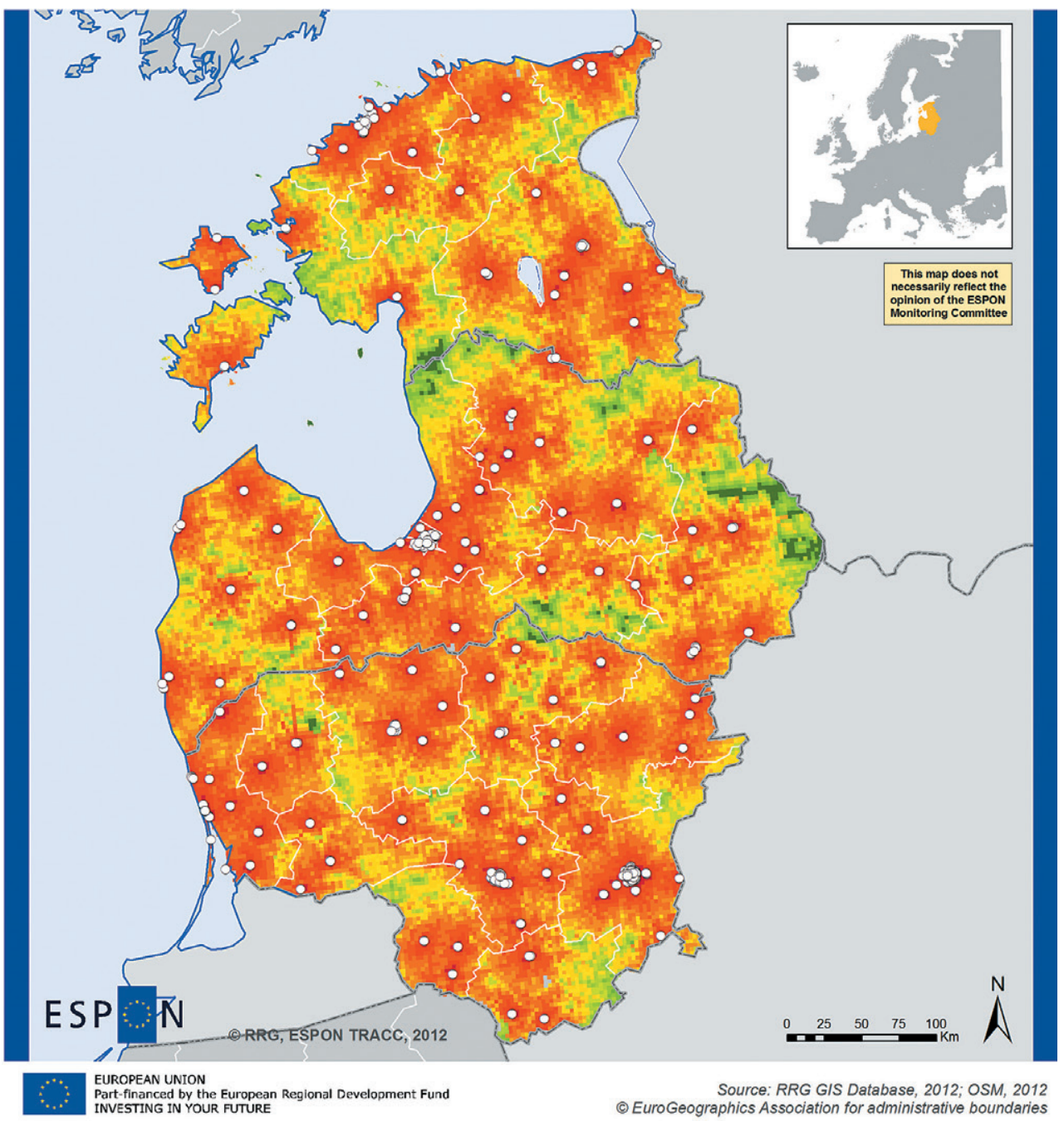

\section{Baltic States Case Study}

Travel time to nearest hospital by road ( $\mathrm{min} ; 2.5 \times 2.5 \mathrm{~km}$ raster), 2012

\begin{tabular}{l|l|l}
$0-5$ & $26-30$ & $51-55$ \\
$6-10$ & $31-35$ & $56-60$ \\
$11-15$ & $36-40$ & $61-65$ \\
$16-20$ & $41-45$ & $66<\ldots$ \\
$21-25$ & $46-50$ &
\end{tabular}

Figure 5. Travel time to nearest hospital by car. 
While Lithuania and Latvia have a rather dense and equally distributed network of general hospitals, even in rural parts, the situation in Estonia is somehow different as hospitals are concentrated only in selected regional cities.

Figure 4 shows that the travel time to the nearest hospital by car is less than 40 minutes for almost all parts of the Baltic States. Only small areas along the Russian borders, and along the border between Estonia and Latvia, so as some Estonian islands, yield travel times of more than 40 minutes. While this overall accessibility level can be considered as fairly good, access to the nearest hospital in emergency cases should be much faster. Isochrones of less than 15 minutes are, however, rather small around the hospital locations. Due to the large number of hospitals, particularly in Latvia and Lithuania, these isochrones nevertheless cover a large part of the population.

At the aggregated regional level, the median travel time lies between 13 (intermediate regions close to a city) and 22 minutes (rural remote regions). Maximum travel times do not exceed 50 minutes for any type of region. Further, $50 \%$ of all people in urban and intermediate regions, representing $50 \%$ of the overall study area population, have a travel time of less than 10 minutes to the nearest hospital, and all people reach the nearest hospital by car in less than 50 minutes. Altogether, the analysis illustrates the extreme spatial imbalance of access to hospitals between urban and rural territories of the Baltic States.

\section{Impact of future TEN-T road network developments}

What impact will the recent TEN-T outline plans, as proposed by the European Commission (2011) in autumn 2011, have on regional accessibility patterns in the Baltic States?

In order to evaluate the impact, the respective TEN-T outline plans were coded into the road and public transport networks, and the indicator regional population accessibility was calculated again for a scenario where all TEN-T projects within the case study area have been implemented. The impacts of these projects are then illustrated by analysing the relative increases in accessibility (Figure 5).

Most of the TEN-T projects in the Baltic States concern improvements in the railway systems. The most important project will be the new high-speed train connection from Tallinn via Pärnu, Riga, and Kaunas towards the Polish border, establishing a continuous rail connection from the north to the south for the first time, even though only few intermediate stops are foreseen. This project is part of the so-called core network Corridor 1 (Baltic-Adriatic Corridor), connecting Helsinki in the north with Ravenna, Italy, in the south via Tallinn-Riga, Warsaw, Katowice, Ostrava, Brno, Vienna, Graz, Villach, Udine and Bologna. The other railway projects concern upgrading the existing lines. Plans include upgrading the links: Tallinn - Narva - Russia, Tallinn - Tartu - Russia, Liepaja/Ventspils - Jelgava - Daugavpils, Riga - Daugavpils, and Kaunas - Siauliai. For Estonia and Latvia, these projects represent almost all main rail lines. In Lithuania, there are no road projects foreseen in the current outline plans, in Latvia there is only one major road project connecting Riga with the east, while for Estonia a number of projects upgrading existing national roads are planned (for instance, Tallinn - Narva, Tallinn - Tartu, Tallinn - Pärnu). 


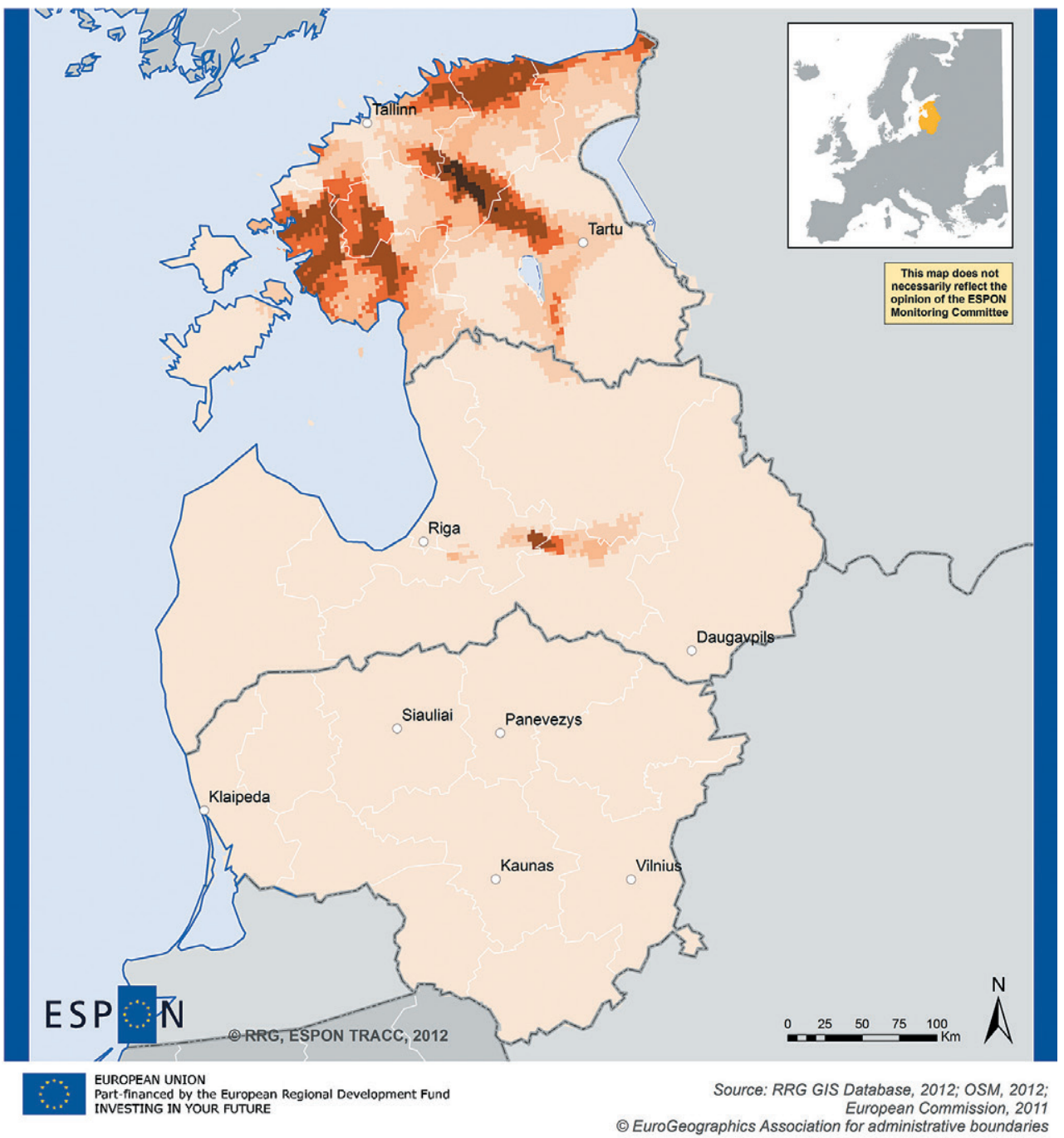

Baltic States Case Study (2011) Relative increase of potential accessibility by car with TEN-T projects (raster)

$0,0-2,5$
$2,6-5,0$
$5,1-7,5$
$7,6-10,0$
$10,1-15,0$
$15,1-20,0$

Figure 6. Relative increase in potential accessibility to population by car with TEN-T projects. 
Comparing accessibility levels before and after the implementation of the TEN-T outline plans, at a first glance only marginal difference can be detected, suggesting that the accessibility patterns will not be revised by these projects. Looking at the relative increases in more detail, in fact the intended projects will have a considerable effect on the accessibility levels of many parts of the study area. The most extensive effect can be found along the road corridor between Tallinn and Tartu, followed by the corridors Tallinn - Pärnu and Tallinn - Haapsalu/Hanila. In addition, accessibility along the corridor Tallinn - Narva will increase considerably. In Latvia, there are only positive impacts measured along the eastward corridor Riga - Laudona, while the rest of Latvia so as entire Lithuania does not benefit from the TEN-T outline plans due to absence of any road projects. Overall, accessibility by car will increase up to $20 \%$ for the most benefitting parts of Estonia.

Despite all positive impacts on accessibility for rural areas in the case study region and for areas along the major transport axes, the existing agglomerations in all three countries clearly benefit the most from the foreseen infrastructure projects so that in total the accessibility patterns with the Baltic States are consolidated and spatial disparities in accessibility are solidified. For Estonia and Latvia, the capital regions of Tallinn and Riga continue to be the major economic and demographic hubs, by far with the highest market potential and the highest accessibility. In the case of Lithuania, it will be interesting to see if and how Kaunas makes use of its improved accessibility (for instance, acting as logistics hub at the crossroads of all north-south and east-west axes) in relation to Vilnius as the demographic and political centre of the country.

\section{Conclusions}

The Baltic States' accessibility analysis managed to successfully depict the various accessibility patterns. The results illustrate different accessibility levels for different indicators, for different modes, for different types of regions, for different spatial levels, as well as for different years. Accessibility of a region cannot be assessed using just one indicator. In this case study, a set of four different accessibility indicators was identified, which should help analysing different aspects of access to markets and to public services. In fact, the results for different indicators have shown that this broad set is quite useful as individual indicators are in fact able to depict different facets and different spatial structures.

The indicator travel time to the nearest regional centre suggests that the service quality by public transport is generally poor for most areas, except for the main agglomerations. In fact, many parts of the Baltic States do not have any public transport access to regional cities. The indicator daily accessibility of jobs marks the dominance of several labour market centres with an extremely high number of jobs, opposed to extensive rural areas where only a fraction of jobs are within reach. The absence of jobs in rural and peripheral areas may, by way of consequence, reinforce migration from peripheral regions towards major centres. Potential accessibility to the population is dominated by Kaunas - Vilnius and Riga. Due to its generally lower population density, Estonia falls behind the performance of the southern parts of the Baltic States. Riga, Kaunas and Vilnius are the largest market areas in the Baltic States in terms of the population potential. The divide in market potentials to rural regions is so high that one expects all future economic and demographic developments concentrate in these agglomerations. Due to even spatial distribution of hospitals across the Baltic States, there is good car access to health care facilities through all parts of the case study area. Only some small 
areas along the border suffer insufficient access times. This indicator confirms a fair and balanced accessibility surface without any polarisation between urban and rural parts.

Calculating accessibility indicators for different points in time or for different scenarios allows assessing the impact of new transport infrastructures or new transport policies. In this case study, actual TEN-T outline plans were used to calculate potential accessibility indicators for a future situation, once these plans are implemented. The results confirm that by applying the defined indicator framework and indicator definitions, impacts of new transport projects can be modelled and analysed. Even though one infrastructure project is unlikely to completely revise existing accessibility surfaces, significant changes to accessibility may be achieved by one project, as it was shown when looking at the relative changes. That way, the accessibility indicators may also be used to analyse territorial cohesion trends. In this study, the scenario was only assessed by using one indicator (population potential accessibility), in future studies similar exercises should be implemented with a broader set of indicators.

Finally, the traditional approaches to accessibility use NUTS regions as spatial units to model at. The present study has proven that even at the level of zoom-in regions, significant intra-regional disparities exist, which cannot be detected by the traditional aggregated models. Such intraregional disparities are often greater than those between regions, thus accessibility studies should acknowledge these disparities and should find ways how to capture them. For the Baltic States, the raster approach turned out to be very useful, and should be developed further. Raster approaches allow capturing the fine grained accessibility surfaces generated by public transport and also reflect the axial structures caused by high-level transport infrastructures. Another advantage of the raster approach is that results can afterwards be easily aggregated to any spatial level, such as LAU2, or higher. In addition, comparisons and crossover correlations with other variables such as population distributions are easy to implement.

Based on the above conclusions, a number of general recommendations can be derived for future accessibility calculations:

- The traditional zone-based approaches should be further developed towards raster-based approaches in order to allow analysing intra-regional accessibility disparities.

- Results at the raster level can then be easily aggregated to any higher spatial zone level (such as NUTS entities or different types of regions) to perform additional statistical analyses, map results, or to serve as a means of easy communication in political processes. In this sense, a combined raster/zonal approach should be implemented.

- Beyond the traditional accessibility indicators of the potential type, new indicators should also be taken into account that reflect access to services of general interest better. In times of demographic change and globalisation, maintaining adequate levels of services of general interest becomes a political challenge. In addition to the indicators applied in this study, access to post offices, banks, or to different types of administrations could also be of interest.

- All accessibility calculations should consider different modes of transport. A restriction to road transport alone is not useful as accessibility patterns for other modes differ considerably from those for cars. 


\section{References}

Biosca O., Spiekermann K., Stępniak M., 2013. Transport accessibility at regional scale. EUROPA XXI, vol. 24, pp. 5-17.

Böhme H., Laaser C.-F., Sichelschmidt H., Soltwedel, R., 1998. Transport in the Baltic Sea Region: Perspectives for the Economic Transition. Kiel: IfW.

Catalog of World Hospitals. 2011. Ranking web of World Hospitals - Hospitals of Latvia. http://hospitals.webometrics.info/hospital_by_country.asp?country=lv [25 September 2013].

Dubois A., Schürmann C., 2009. Transport and Accessibility in the Baltic Sea Region - structures and perspectives. [in:] BBR (ed.), Raumplanung und -entwicklung in der Ostseeregion. Informationen zur Raumentwicklung, 8/9.2009, Bonn: Bundesamt für Bauwesen und Raumordnung, pp. 547-560.

EEA - European Environment Agency, 2012. Population density disaggregated with Corine Land cover 2000. Copenhagen: EEA, http://www.eea.europa.eu/data-and-maps/data/population-density-disaggregated-with-corine-land-cover-2000-2 [25 September 2013].

Eesti Haigekassa. Estonian Health Insurance Fund, 2012. The list of Hospitals in Estonia. www. haigekassa.ee/eng/service/specialised-medical-care/hospitals.html [25 September 2013].

Eesti Hariduse Infosüsteem, 2012. Estonian Education Information System. http://www.hm.ee/koolikaart/ [25 September 2013].

European Commission, 2011. Annex to the Proposal for a Regulation of the European Parliament and of the Council on Union Guidelines for the Development of the Trans-European Transport Networks. Brussels: European Commission.

Eurostat, 2012. Doctors per 100,000 inhabitants in 2009. Regio Database, table hlth_rs_spec. Luxembourg: Eurostat.

Hospitals Worldwide, 2012. Lithuanian Hospitals Directory-Lithuanian Hospitals and Health Clinics. www.hospitalsworldwide.com/countries/lithuania.php [25 September 2013].

Lanet, 2012. Schools and school related $W W W$ pages in Latvia. www.lanet.lv [25 September 2013].

Lietuvos Medicina, 2012. List of Hospitals and Clinics. www.medicina.lt [25 September 2013].

Neogeo.lv, 2012. Latvijasskolukarte. http://neogeo.lv/?p=4278 [25 September 2013].

OAG, 2012. Air Route Information. Direct Destinations from/to and to/from. Bedfordshire: OAG Worldwide Limited.

OSM - OpenStreetMap, 2012a. Road networks for Estonia, Latvia and Lithuania. www.openstreetmap.org [25 September 2013].

OSM - OpenStreetMap, 2012b. Hospital locations in the Baltic States. www.openstreetmap.org [25 September 2013].

OSM - OpenStreetMap, 2012c. Schools in the Baltic States. www.openstreetmap.org [25 September 2013].

RRG - RRG Spatial Planning and Geoinformation, 2012. RRG GIS Database. Trans-European Transport Networks. Oldenburg: RRG.

Schmitt P., Dubois Al. (ed.), 2008. Exploring the Baltic Sea Region - On Territorial Capital and Spatial Integration. Nordregio Report 2008:3, Stockholm: Nordregio.

UNDP - United Nations Development Programme, 2012. International Human Development Indicators. New York: UNDP, http://hdr.undp.org/en/statistics/. 
UNECE - United Nations Economic Commission for Europe, 2008. UN-ECE E-Road Census 2005.

Geneva: UNECE.

Wikipedia, 2012a. Estland. http://de.wikipedia.org/wiki/Estland [25 September 2013].

Wikipedia, 2012b. Lettland. http://de.wikipedia.org/wiki/Lettland [25 September 2013].

Wikipedia, 2012c. Litauen. http://de.wikipedia.org/wiki/Litauen [25 September 2013].

Wikipedia, 2012d. List of Hospitals in Estonia. http://en.wikipedia.org/wiki/List_of_hospitals_in_ Estonia [25 September 2013].

Wikipedia, 2012e. List of Hospitals in Latvia. http://en.wikipedia.org/wiki/List_of_hospitals_in_ Latvia [25 September 2013].

Wikipedia, 2012f. List of Hospitals in Lithuania. http://en.wikipedia.org/wiki/List_of_hospitals_in_ Lithuania [25 September 2013].

Wikipedia, 2012g. List of schools in Estonia. http://en.wikipedia.org/wiki/List_of_schools_in_Estonia [25 September 2013].

Wikipedia, 2012h. List of schools in Lithuania. http://en.wikipedia.org/wiki/List_of_schools_in_ Lithuania [25 September 2013]. 